\title{
The 4th ASME-ISPS/JSME-IIP joint international conference on micromechatronics for information and precision equipment, Santa Clara, California, USA
}

\author{
Eng Hong Ong $\cdot$ Kenji Fukuzawa $\cdot$ Jen-Yuan Chang
}

Published online: 31 July 2013

(c) Springer-Verlag Berlin Heidelberg 2013

It was our great honor and pleasure to host the 4th ASMEISPS/JSME-IIP Joint International Conference on Micromechatronics for Information and Precision Equipment (MIPE 2012) at Santa Clara University, Santa Clara, California, USA from June 18 to June 20, 2012. The MIPE conference has come a long way since its inauguration in 2003, ASME and JSME have since been jointly organizing the conference every 3 years.

MIPE 2012 was a very unique conference which offers an ideal platform for researchers from both academic and industry to present their latest research outcome, exchange ideas and explore collaborate opportunities. The conference covered a wide spectrum of research topics in areas that include magnetic and optical storage systems, information processing systems, nano/micro-electrical-mechanical systems, recording material, sensor networks, biomedical equipment and so on; and two new technical sessions, Sensor Networks and Wearable Information Devices and Future Technologies and Advanced Topics were also introduced to the conference. Papers presented at the conference highlighted scientific and technological advancements in:

\footnotetext{
E. H. Ong

Singapore University of Technology and Design,

Singapore, Singapore

e-mail: enghong_ong@sutd.edu.sg

K. Fukuzawa

Nagoya University, Nagoya, Japan

e-mail: fukuzawa@nuem.nagoya-u.ac.jp

J.-Y. Chang ( $\square)$

Department of Power Mechanical Engineering,

National Tsing Hua University, Hsinchu, Taiwan

e-mail: jychang@pme.nthu.edu.tw
}

- Head/media interface and tribology

- Drive mechanisms

- Servo control

- Micro/nanomechatronics

- Biomedical equipment

- Intelligent machines and brain science applications

- Flexible media handling machines and printed electronics

- Imaging and printing technologies

- Precision equipment

- Micro/nanosystem science and technology

- Simulation of nanoscale phenomena

- Opto-mechatronics

- Consumer electronics

- Future technology/Symposium on advanced topics

- Sensor Networks and wearable information devices

MIPE 2012 had seen a very fruitful and meaningful collaboration between ASME and JSME. We had put together about 140 presentations covering the abovementioned areas for the 3-day conference, and we were pleased to have Pantelis Alexopoulos (Executive Director, A*STAR Data Storage Institute) and Harlan Kragt (Vice President of Head Mechanical R\&D, Seagate Technology) as our keynote speaker and conference dinner banquet speaker, respectively.

To have proper documentation for the ease of reference in future, authors of presentations at the conference were invited to submit their full papers for consideration of publication in this special issue of Microsystem Technologies. All papers submitted went through a rigorous peer review process; many reviewers are leading experts in their areas of research and many of the papers had gone through a number of revisions before they were accepted for publication in the journal, so that quality of the journal was 
upheld. We would like to take this opportunity to express our sincerest gratitude to all our reviewers, who, despite their tight work schedule, have helped us review the papers in a timely manner on a voluntary basis. Without their great efforts, this special issue of Microsystems Technologies would not have been published in time.

We would also like to take this opportunity to thank Santa Clara University for the use of its facilities for MIPE 2012, Dr. Neal Schirle as the Conference Treasurer and for making the necessary arrangements with Santa Clara University, both Dr. Jie Yu and Professor No-Cheol Park for designing the conference program, and both Professor
Jen-Yuan (James) Chang and Professor KS Park for designing and maintaining the conference website.

Special gratitude is also extended to the executive members of ASME-ISPS and JSME-IIP, members of the Conference Advisory Committee, session organizers, and session chairs and co-chairs, they have put in much effort to bring MIPE 2012 into being.

Last but not least, a final word of gratitude goes to all presenters and participants at the conference. The MIPE 2012 would not have been successful without your dedicated participation. 